\title{
Pobres, gitanos y excluidos: estudio de caso de un asentamiento gitano
} María José Lera *

\section{Resumen}

El pueblo gitano ha sido históricamente marginado y excluido socialmente, y en la actualidad aún existen asentamientos extremadamente pobres de familias de etnias gitanas en Andalucía. Nos hemos acercado a un asentamiento gitano muy particular para explorar sus niveles de pobreza, sus condiciones de vida y su impacto en el desarrollo infantil. Esta intervención se ha realizado al mismo tiempo que se denunciaba la falta de atención por parte de las autoridades públicas a un colectivo de pobreza crónica y extrema que a medida que pasa el tiempo acumula infortunios y tragedias en sus vidas. Lo malo se acumula en los más pobres, incrementando el nivel de sufrimiento en los más vulnerables, y destacando el papel del tiempo en el éxito de las intervenciones sociales.

\section{Palabras clave}

Pobreza extrema; Pobreza crónica; Miseria; Exclusión social; Gitanos; Desarrollo infantil; Resiliencia

\section{Abstract: Poor, gypsies and excluded: study of case of a gypsy accession}

The gipsy people have been traditionally marginalised and socially excluded, and still today there are families that live under extremely poverty conditions in Andalusia. We have been observing a gypsy family very particular: their level of poverty, their living conditions and the impact of such features on children development have been explored. While this intervention has been carried out, the lack of involvement from local authorities have been denounced, who are dedicating less attention to the people who are more in need, so tragedies and extremely difficult situations are increasing in that family. All the bad things come together, increasing the suffering of the most vulnerable people, and pointing out the importance of timing in the success of social interventions.

\section{Key words}

Extreme Poverty; Chronic Poverty; Misery; Social Exclusion; Gypsies; Childhood Development; Resilience. 


\section{Pobreza y desarrollo}

El desarrollo de niños y niñas se ve afectado por las condiciones del entorno en el que viven, y un ejemplo de ello se puede observar en los menores que viven en condiciones de pobreza. Numerosas investigaciones señalan que los niños y niñas que viven en entornos desfavorecidos presentan bajo cociente intelectual, bajo nivel sociocultural, menos cualidades positivas en sus hogares, son generalmente menos competentes y con más problemas de comportamientos disruptivos y de vivir más situaciones de estrés (Masten et al., 1988).

Las condiciones de pobreza, especialmente cuando es crónica, afectan al desarrollo cognitivo y socioemocional de quienes lo sufren (McLoyd, 1998). En un estudio longitudinal estadounidense reciente se vuelve a confirmar que los peores niveles de lectura y lenguaje corresponden a niños y niñas de familias pobres (National Institute of Child Health and Human Development Early Child Care Research Network, 2005), resultados que se ven confirmados igualmente en investigaciones realizadas en España (Lera, 1994).

Estudios realizados desde una perspectiva ecológica (Bronfrenbrenner \& Cecci, 1994) muestran igualmente el impacto de las macro-variables (estatus social, nivel económico) en el desarrollo infantil, y su efecto acumulativo. Las familias más pobres tienen más problemas, más circunstancias negativas, siendo este efecto acumulativo un agente real de desventaja (Combs-Orme \& Cains, 2006), y se confirma el paradigma de que los pobres seguirán siendo pobres, pues las peores condiciones les acompañan a lo largo de su vida (Emerson, 2004).

Si las condiciones de pobreza se perpetúan, y son acumuladas por generaciones, sus efectos se multiplican afectando aún más a los más pequeños. Diversos estudios señalan que el estrés aso- ciado a la pobreza golpea doblemente a los niños menores de seis años; estos menores pobres serán doblemente castigados, por el estrés de la pobreza de su familia y por el especial impacto de éste en su desarrollo emocional y afectivo (Wadsworth et al., 2008).

Parece, pues, que si la pobreza es crónica conlleva el "efecto negativo en cadena" donde toda una serie de episodios estresantes aparecen en la vida del individuo, sin posibilidad de dar una respuesta adecuada, lo que aumenta su impotencia, nivel de estrés y depresión, y el círculo continúa (Rutter, 1987). Esta perspectiva a veces se ha interpretado como la incapacidad de romper este círculo de empobrecimiento, derivando en la aceptación de la continuación de tal ciclo, en parte fundamentado en que las experiencias infantiles determinan el éxito adulto en la vida.

El colectivo de "gitanos", es decir, personas que son consideradas de la etnia gitana (aún sin poder identificarse por ningún fenotipo ni genotipo delimitado), cuya mayor proporción está representada dentro de España en Andalucía, comparten una situación que caracteriza al pueblo gitano de vivir en la marginalidad, pobreza extrema, miseria, persecución, exclusión social y supervivencia. En algunas situaciones los gitanos sí tienen un estatus social que les permite una vida digna, pero no son la mayoría. Por el contrario, siguen viviendo en guetos de viviendas (chabolismo), en guetos escolares (se concentran en algunos centros), su trabajo más frecuente es marginal y pobre (chatarreros), características que arrastran desde hace más de 400 años (Pabanó, 1915). Esta miseria acumulada les lleva a vivir en un medio en el que son una minoría, excluida y pobre, y cuya situación se explica por ellos mismos, es decir, se culpa a la víctima de su propia situación sin tener en cuenta los efectos que las vivencias de esta pobreza crónica y extrema tiene en el desarrollo de las capacidades de sus niños y niñas. 
Presentamos en este artículo un estudio de caso, de un asentamiento muy particular, al estar constituido por una única familia extensa, de etnia gitana-andaluza ("siempre han sido de aquí", dicen ellos mismos), de pobreza extrema, crónica, y con todos los componentes asociados imaginables (deficientes físicos, psíquicos, desórdenes mentales y familias muy numerosas).

\section{Pobres, gitanos y excluidos: presentación de un estudio de caso}

En Alcalá de Guadaíra (Sevilla) existe un asentamiento muy particular, se trata de los miembros de la familia extensa RG, la cual desde hace aproximadamente diez años comienza a vivir en la zona. El asentamiento (conocido como de La Verea) se compone originariamente de seis grupos familiares con características muy especiales; es prácticamente un matriarcado con muchos hijos y con minusválidos. Realizamos el primer estudio en el año 2004, el cual mostraba la siguiente realidad (ver Cuadro 1):

\begin{tabular}{|l|l|l|l|l|l|}
\hline $\mathbf{2 0 0 4}$ & Miembros & Discapacitados & \multicolumn{2}{|c|}{ Cabeza de familia } & Menores de 16 años \\
\hline Familia 1 & 5 & 1 (padre) & madre & padre & 6 \\
\hline Familia 2 & 8 & & madre & & 8 \\
\hline Familia 3 & 9 & & madre & & 0 \\
\hline Familia 4 & 5 & 1 (madre) & madre (discapacitada) & & 3 \\
\hline Familia 5 & 6 & 1 (hijo) & madre (viuda) & padre & 3 \\
\hline Familia 8 & 5 & 0 & madre & $\mathbf{2}$ & $\mathbf{2 3}$ \\
\hline TOTAL= 6 & $\mathbf{3 8}$ & $\mathbf{3}$ & $\mathbf{6}$ & & \\
\hline
\end{tabular}

Cuadro 1. Familias del asentamiento de La Verea en 2004. Fuente: Elaboración propia.

- Familia 1: compuesta inicialmente por tres hijos menores de 18 años, padre con minusvalía psíquica y física, con incapacidad total, y la madre que es la principal de la casa.

- Familia 2: compuesta por ambos padres y seis hijos (tres niñas y tres niños, todos menores de diez años), el padre es el hijo de la familia 1 y la madre es hija de la familia 4.

- Familia 3: compuesta por la madre y tres hijos y cinco hijas, todos menores de 14 años, el padre lleva muchos años en la cárcel.

- Familia 4: compuesta por la madre y una hija y tres hijos -todos mayores de 18 años-, el padre que está en la cárcel, la madre tiene una minusvalía física importante que casi le impide caminar.

- Familia 5: compuesta por la madre (viuda) y 6 hijos (tres chicos y tres chicas), uno de ellos minusválido físico y psíquico, que tampoco puede caminar, y tres hijas menores de 16 años.

- Familia 8: ambos padres y 3 hijos menores de cinco años. En esta familia no hay minusvalías.

Nos encontramos, pues, con un núcleo familiar de cuatro hermanas y un hermano, además de uno de sus hijos, con unos 23 menores de edad y tres disminuidos físicos y psíquicos.

Esta extensa familia pertenece a la etnia gitana, y ellos se definen a sí mismos como gitanos andaluces. Han vivido siempre por la zona, apegados al campo y con movilidad condicionada por la recogida de aceitunas $u$ otras tareas del campo. Su nivel educativo es de total analfabetismo, no sólo en relación a la lectura sino también en cuanto al conocimiento de números y las pautas cotidianas, como es entender un almanaque o poder leer las horas del reloj. 
Los ingresos que tienen son en general por el número de hijos pequeños que tienen -lo conocido como "los puntos" que se cobran cada seis meses-. Los hombres se dedican a la recogida de chatarra y las mujeres a pedir en el pueblo. Todos los menores mayores de tres años están escolarizados en el centro educativo más cercano a la zona; no obstante el acceso al mismo es a través de una carretera sin arcén y peligrosa por la que tienen que caminar empujando los carros de los bebés más pequeños, por lo que se quejan del mismo.

Ante esta situación se inició un estudio realizado por el grupo de investigación "Fundamentos en intervenciones psicoeducativas" (HUM-166) para analizar el grado de pobreza y condiciones en las que sobrevivían. Una mirada más profunda nos permitió conocer a un colectivo que sobrepasa los límites de la pobreza, al confirmar su nulo acceso al pueblo (del que están alejados unos siete kilómetros) y unas condiciones de vida realmente insalubres para los mayores, los menores y toda persona que allí viva. Las viviendas son calificadas oficialmente como "infraviviendas", es decir, casas con techos de uralita y con agujeros, sin instalación de agua, ni aseo, ni ventanas, ni puertas, con suelos de tierra y sin muebles, sin mesa, sillas, ni siquiera con qué cocinar. La basura se acumula por doquier, lo que hace que ratas $y$ otros animales sean los compañeros habituales de sueños y temores de los que allí habitan.

Se realizó un informe que fue enviado a la Delegación de Asuntos Sociales y a la de Educación de Alcalá, así como al centro educativo, para dar a conocer esta realidad a las autoridades pertinentes (Lera, 2005b; Lera, Allepuz y Mateo, 2005).

\section{Intervenciones en verano}

Durante el verano las condiciones de los menores son, si cabe, aún más duras, pues tienen que soportar las altísimas temperaturas propias de esta zona (valle del Guadalquivir), sin tener el apoyo del comedor escolar ni la realización de ninguna actividad. Es por ello que en el verano de 2005 solicitamos a la Delegación de Educación de Alcalá de Guadaíra una subvención mínima para abrir el centro durante el mes de julio y al menos proporcionar actividades y comida para los 15 niños y niñas del asentamiento.

El Ayuntamiento nos ofreció una ayuda para cubrir los gastos de comida de los menores, que desayunaban hasta tres veces durante las tres o cuatro horas que estaban en el centro realizando actividades varias con la colaboración de estudiantes de la Universidad de Sevilla. El éxito de la escuela fue total; no sólo no faltaban sino que todos querían ir todos los días: comíamos, jugábamos, contábamos cuentos, volvíamos a comer, pintábamos, o teníamos experiencias con el agua (Lera, 2005a). Al regreso del curso escolar, nos fue reiterada la disconformidad de la dirección del centro con la experiencia llevada a cabo, prohibiendo por tanto la realización de la misma en años sucesivos.

En el año 2009 esta actividad fue retomada por el Secretariado del Pueblo Gitano y suspendida en el 2010, por desaprobación de la misma por la dirección del centro educativo donde se realizaba.

\section{Transporte y desayuno}

En octubre de 2006, nos convocaron a una reunión en la Delegación de Educación municipal en la que expusimos nuestras demandas, que eran disponer de un autobús, desayuno escolar, aseos, ropa y solicitar un proyecto de educación compensatoria para el centro. Las demandas fueron negadas por razones estratégicas, es decir, las autoridades de Alcalá consideraban que el autobús no era su competencia, que el desayuno lo tenían que proporcionar las madres como parte de un programa reeducativo y que el aseo personal no era competencia del centro educativo (Pérez Llorente, 2006). 
Ante estas negativas, seguimos solicitando el autobús y, tras una gestión con la Delegación de Educación de Sevilla, ésta aceptó financiarlo. Desde el curso académico 2006 cuentan con un autobús que recoge a los niños del asentamiento y los vuelve a dejar en el mismo cuando ha terminado la jornada escolar. Tras presentar el caso al Defensor del Pueblo, el centro escolar presentó un programa de compensatoria, si bien los niños y niñas siguen cinco años después sin tener actividades extraescolares, siendo su horario de 9:00 a 14:00, incluido el comedor en estas horas. La comida sí ha sido siempre proporcionada por el ayuntamiento a los niños de manera gratuita, aunque a veces las madres se han quejado de que no permitían a los niños repetir la comida, acto que no hemos podido confirmar in situ, pero que ha sido comentado por madres y escolares.

\section{Comida y alimentos}

Una de las necesidades básicas era la comida; en este sentido se consiguió un acuerdo con el Banco de Alimentos de Sevilla, quienes a través de una voluntaria religiosa cada dos semanas entregaba comida a estas familias; sin embargo, la situación empeoraba a medida que transcurría el tiempo. Las familias crecieron, y las madres jóvenes continuaban teniendo hijos; los mayores se iban casando entre ellos aumentando por tanto el número de familias y de menores en estas condiciones. La comida proporcionada era y es una ayuda, pero no sirve para evitar el problema de la inadecuada nutrición.

\section{Ilusiones y deseos}

Dado que era imposible para el equipo de investigación ofrecer una respuesta adecuada y paliar las necesidades básicas del colectivo, decidimos llevar a cabo acciones psicoeducativas, con el objetivo de fortalecer la resiliencia en ellos. Es decir, mejorar sus expectativas de vida, abrir ventanas a la esperanza y apoyar su dignidad como personas. En este sentido llevamos desde el año 2005 hasta la actualidad realizando la campaña "Cinco deseos por Navidad".

El objetivo es proporcionar un apoyo social instrumental (entrega de juguetes), de compañía (visita afectuosa de personas), aunque no sea duradera, y de mejora de la autoestima e identidad al pedirle a cada niño y niña del asentamiento que nos dijeran "sus" cincos deseos por Navidad, que los estudiantes intentarían cumplirlos. Un grupo de estudiantes de $5^{\circ}$ de Psicología se hace cargo de visitar a los niños y pedirles que soliciten sus deseos, que se anotan y se buscan. Se pretende mejorar la autoestima, el locus de control interno y sentir el apoyo social y afectivo de un grupo de personas.

Los deseos que piden vuelven a mostrar la humildad, pobreza y necesidad de estos menores, siendo lo más solicitado el chándal y los botines, las bicicletas, así como los típicos juguetes de niño (coche, camión...) y de niña (muñecas, carritos...). Juguetes que claramente hacen diferente a este colectivo de cualquier otro de mayor nivel sociocultural (Lera, 2009, p. 89).

El día de la entrega de los deseos es una fiesta para todos, lo intentamos hacer lo más cercano posible al 25 de diciembre, y antes de que los estudiantes inicien sus vacaciones, por lo que generalmente el 22 de diciembre de cada año los "reyes magos", como ellos nos llaman, visitan el asentamiento. Generalmente un grupo de unos 150 estudiantes participan y, ayudados por sus familias y amigos, no sólo cumplen los deseos de los niños y niñas, sino que intentan paliar las dificultades de las familias con la entrega de ropa, mantas y comida para todos. Generalmente nos encontramos allí unas 250 personas, en unos 80 coches, lo que hace realmente la experiencia todo un acontecimiento. Es importante añadir que vamos siempre, llueva o no llueva, haga frío o viento -se pueden ver algunas imágenes de esta activi- 
dad en el vídeo "Cinco deseos por Navidad: Navidades 2006" (Fuentes, 2007)-.

\section{Acompañamiento y denuncias}

A estas actuaciones les han seguido otras medidas como es el acompañamiento a estas familias a la resolución de problemas o solicitud de soluciones en la Delegación de Vivienda, asuntos judiciales, solicitud de empleo, visita a asuntos sociales, o ayuda directa llevándolos al médico o llamando a una ambulancia cuando ha hecho falta. Además se ha continuado enviando informes periódicos al Defensor del Pueblo, quien ha contactado con las autoridades dada la gravedad de los hechos (Lera, 2008).

La respuesta a estas denuncias se concreta en una propuesta del Ayuntamiento de un plan integral para este asentamiento, el cual no se nos ha facilitado, por lo que ignoramos cuáles son las medidas concretas a tomar. Sí sabemos que la actuación ha sido financiada por la Diputación de Sevilla para atender especialmente un asentamiento grande que se encuentra en el término de Alcalá pero muy cercano a Torreblanca, que tiene al menos 80 familias, en su mayoría gitanos portugueses, con acceso a agua, a electricidad, así como a los recursos básicos del núcleo urbano cercano que está a menos de un kilómetro. También reciben asistencia de Cáritas y otras organizaciones caritativas, por lo que la naturaleza del mismo, siendo extrema, es diferente al de la familia extensa del asentamiento de la Verea (al que nos estamos refiriendo). Dada la presión recibida por los informes emitidos al Defensor, desde la Delegación de Asuntos Sociales de Alcalá deciden que con el presupuesto obtenido se incluya también a la extensa familia RG en el plan especial.

Ante la falta de actuaciones y la denuncia pública de la situación, a nivel educativo contacta con nosotros la asociación del Secretariado del Pueblo Gitano, quien comienza a intervenir desde la escuela proporcionando ayuda directa a las familias (ropa, solicitud de ayuda de La Caixa, etc...) y ofrecen una escuela de verano. Estas actividades han sido interrumpidas a medida que el "plan" de intervención avanzaba, quedando los niños nuevamente sin actividades en verano, y fue la única vez que fueron a una piscina y al teatro. Al parecer, la falta de colaboración por parte del equipo directivo ha sido lo que les ha impedido continuar. Sin embargo, en el año 2010 la situación no solamente sigue a peor, sino que la gravedad se hace extrema al perder el acceso a la electricidad, lo que les lleva a vivir sin luz y sin agua (pues los motores no funcionan para extraer el agua del pozo). En esta situación llevan desde febrero de 2010, fecha en que por causas atmosféricas se rompió el transformador, que nunca ha sido ni será reparado. Ante esta situación de indefensión, sin agua, sin luz, con frío, y con numerosos niños y niñas, decidimos realizar una acción de reclamo de sus derechos. Para ellos escribimos una carta denunciando la situación y toda la legalidad que desde el ayuntamiento se estaba incumpliendo, y fuimos con ellos a presentar el escrito en registro haciendo uso de sus derechos como ciudadanos (Lera, 2010a).

La situación no pudo ser más surrealista, pues fuimos recibidos por la policía quien les impidió entrar en el ayuntamiento para presentar su firma. El apoyo recibido por numerosas organizaciones y partidos políticos del pueblo y de Sevilla fue masiva, de manera que nuestro colectivo se vio apoyado por la ciudadanía, quienes también firmaron el escrito, los acompañaron en su exclusión del edificio del Ayuntamiento, y se comprometían a seguir luchando para denunciar esta discriminación justamente de quiénes más lo necesitan.

Este acto finalizó con una reunión con los responsables del ayuntamiento, quienes volvieron a repetir que no buscarían ninguna solución, espe- 
cialmente las demandas de solicitud de una vivienda de protección oficial en régimen de alquiler y el acceso a un puesto de trabajo por sus condiciones de exclusión social; estas demandas no se cumplirían nunca. Ésta fue su respuesta (Lera, 2010b).

\section{Situación actual}

En febrero de 2010 la situación de la familia extensa $R G$ residente en el asentamiento de la Verea es la que se refleja en el Cuadro 2.

\begin{tabular}{|l|l|l|l|l|l|}
\hline $\mathbf{2 0 1 0}$ & Miembros & Discapacitados & Menores 16 Años & \multicolumn{2}{|l|}{ Cabeza De Familia } \\
\hline Familia 1 & 3 & 2 (padre e hijo) & 0 & madre & \\
\hline Familia 2 & 12 & 0 & 10 & madre & padre \\
\hline Familia 4 & 7 & 1 (madre) & 2 & madre & \\
\hline Familia 4b* & 7 & 0 & 5 & madre & padre \\
\hline Familia 5 & 5 & 1 (hijo) & 2 & madre & \\
\hline Familia 7 & 7 & 0 & 5 & madre & padre \\
\hline Familia 8* & 6 & 0 & 4 & madre & padre \\
\hline TOTAL= 7 & $\mathbf{4 7}$ & $\mathbf{4}$ & $\mathbf{2 8}$ & $\mathbf{7}$ & $\mathbf{4}$ \\
\hline
\end{tabular}

Cuadro 2. Familias del asentamiento de La Verea en febrero de 2010. Fuente: Elaboración propia.

Quizás por las presiones recibidas, o por el cumplimiento del plan, en el verano de 2010 a una de las familias (la $4 b^{\star}$ ), compuesta por cinco hijos menores de 6 años, le fue proporcionado un piso en el pueblo, el cual tienen que pagar a una media de 400 euros al mes, es decir, a precios del mercado, y para ello tienen que dar todas las ayudas que obtienen tanto de los "puntos" de los niños, del salario social, y de otras ayudas de La Caixa que estaban disfrutando.
En mayo de 2011 la familia 8*, compuesta por cuatro hijos y el matrimonio, también se marcha a vivir a un piso en Alcalá, nuevamente alquilado a precios de mercado. Así que en junio de 2011 la realidad es la que sigue, con el compromiso de seguir buscándoles casas o pisos a precios de mercado para que se vayan yendo; y, como vemos, la frecuencia es una familia por año, y las que han sido atendidas son las que no tienen ningún discapacitado entre ellos.

\begin{tabular}{|l|l|l|l|l|l|l|}
\hline $\mathbf{2 0 1 1}$ & Miembros & Discapacitados & Menores & Cabeza De Familia & Residencia \\
\hline Familia 1 & 3 & 2 & 0 & madre & & La Verea \\
\hline Familia 2 & 12 & 0 & 10 & madre & padre & La Verea \\
\hline Familia 4 & 7 & 1 & 2 & madre & & La Verea \\
\hline Familia 5 & 5 & 1 & 3 & madre & & La Verea \\
\hline Familia 7 & 7 & 0 & 5 & madre & padre & La Verea \\
\hline TOTAL= 5 & $\mathbf{3 4}$ & $\mathbf{4}$ & $\mathbf{2 0}$ & $\mathbf{5}$ & $\mathbf{2}$ & \\
\hline
\end{tabular}

Cuadro 3. Familias del asentamiento de La Verea en junio de 2011. Fuente: Elaboración propia.

\section{Pero... ¿son realmente pobres?}

Curiosamente la primera investigación se inicia por una demanda de la dirección del centro educativo, en donde tenían discusiones entre el profesorado por no saber ciertamente si eran pobres o sólo lo parecían. El informe presentado no dejaba lugar a dudas, este colectivo sufre de una pobreza crónica y extrema, en unas condiciones difícilmente comparables con las de cualquier otro, sin embargo, justamente sus características tan particulares estaban siendo y son actualmente 
ignoradas (Lera, 2005b).

Las medidas de la pobreza no son ni fáciles ni están homogeneizadas; tomando como referencia los indicadores usados en Estados Unidos, se incluyen las medidas absolutas y las medidas relativas (Roosa, Deng, Nair, \& Burrel, 2005, p. 972). Utilizaremos estos indicadores para evaluar si este colectivo realmente es pobre y en qué grado, pues el grado de pobreza condiciona el tipo de ayudas a las que se puede acceder y el grado de prioridad de las mismas.

En medidas absolutas se consideran los ingresos por año y el coste de la comida, teniendo en cuenta el tamaño de la familia. En la Unión Europea se define pobreza absoluta si no se llega al $60 \%$ del nivel medio, es decir, que si el nivel medio español o andaluz está en 1000 euros, estas familias no llegan ni a 400 , es decir, ni el $40 \%$. Si tenemos en cuenta el número de miembros (tienen de 4 a 10 hijos), nos llega a una media entre 70 a 30 euros al mes para sobrevivir, por lo que estas familias cumplen el criterio de pobreza absoluta, pero extrema ya que no llegan ni al $40 \%$ en relación a la media, y ni al $10 \%$ cuando se tienen en cuenta el número de miembros de las mismas.

Como medidas relativas se tiene en cuenta el nivel socioeducativo que determinan sus competencias para sobrevivir en un entorno de un país desarrollado. En esta familia extensa son todos analfabetos y sin estudios. Se añaden además los problemas económicos, generados por tener multas de tráfico por conducir sin carnet, multas atrasadas de teléfono y pleitos, además de los problemas de subsistencia básica (comida), que intentan paliar pidiendo limosna. Se añade la inseguridad alimenticia y hambre; la comida la buscan en contenedores de basura, la piden, o simplemente consiguen pan duro. La comida proporcionada por el Banco de Alimentos es una ayuda, pero no cubre sus necesidades. La exclusión so- cial y distanciamiento físico del pueblo añaden problemas de salud (problemas de piel, resfriados, etc...), problemas de higiene, dado que no tienen agua ni condiciones mínimas; además las jóvenes tienen embarazos adolescentes.

Teniendo en cuenta tanto las medidas relativas como las absolutas, este colectivo vive en unas condiciones de pobreza extrema; si tenemos en cuenta que estas condiciones han sido incluso peores en sus generaciones anteriores -dato confirmado por ellos- y compartido por los gitanos de la zona, se llega a concluir que esta pobreza no sólo es extrema sino además crónica, lo que perpetúa sus vivencias en la miseria, por ser pobres y gitanos (Lera, 2009).

\section{Impacto en el desarrollo infantil}

Con el objetivo de observar si estas condiciones de vida tienen un impacto en el desarrollo infantil, en el primer informe se analizaron los niveles de desarrollo lingüístico y social de los niños de edad escolar que en ese momento -2004- estaban en el asentamiento. Los datos aparecen en el informe redactado (Lera, 2005b), de los cuales proporcionamos aquí un resumen.

\section{El lenguaje}

En el estudio realizado en el 2004 se tomaron medidas del desarrollo lingüístico de niños y niñas. Seleccionamos el test de Vocabulario Peabody (Dunn, 1985). Este test consiste en presentar un conjunto de cuatro imágenes, se dice en voz alta un nombre que el niño o niña tiene que señalar. Al número de respuestas acertadas le corresponde una Edad Equivalente que es comparada con su Edad Cronológica. Se siguieron las instrucciones del test Peabody en su versión española.

La muestra estudiada era de 14 niños y niñas del asentamiento (10 niñas y 4 niños), de edades comprendidas entre los 5 y 12 años, y cuyos datos mostraron una media de 5,79 , es decir, un 
retraso de dos a tres años en su desarrollo, que además se acentuaba con la edad, pues se observó un efecto acumulativo, siendo mayor el retraso conforme los niños y niñas avanzaban en edad.

La diferencia entre su Edad Equivalente (según el test) y su Edad Cronológica a la fecha de la administración de las pruebas es 3,6 es decir, de 3 años y medio respecto a su edad. Esta diferencia obviamente es estadísticamente significativa, pero su significatividad social debería ser espe- cialmente considerada pues se vuelve a confirmar el impacto del contexto familiar en el desarrollo infantil.

Una pregunta más que nos hemos hecho es la relación entre esta diferencia en el desarrollo del lenguaje y la edad cronológica. Para ello hemos hecho una correlación de Pearson entre la variable diferencia y la edad. Los datos señalan que existe una relación negativa, es decir, que cuanto más edad tienen los niños y niñas, mayor es esta diferencia (ver Cuadro 4).

\begin{tabular}{|l|l|r|r|c|}
\hline $\mathbf{N}=\mathbf{1 4}$ & Media & Diferencia & Correlación de Pearson & Sign. \\
\hline Edad cronológica & 8,3 & -3.6 & -.793 & .001 \\
\hline Edad equivalente & 4,7 & & & \\
\hline
\end{tabular}

Cuadro 4. Correlación entre edad y desarrollo lingüístico en el asentamiento de La Verea. Fuente: Elaboración propia.

\section{El desarrollo social}

Las medidas de desarrollo social consisten en un cuestionario (CBI) (Shaefer, Edgerton, \& Aaronson, 1978), que el profesorado completa pensando en las capacidades de cada alumno o alumna. Consta de un total de 42 ítems, que a su vez se clasifican en ocho subescalas que permiten obtener una puntuación de 1 a 4 en las siguientes medidas:

- Extraversión: habilidades del niño para establecer relaciones con los otros, tener sentido del humor, expresar sus propias ideas, liderar un grupo, etc.

- Creatividad: habilidades que muestran interés y curiosidad, preguntas sugerentes, propuestas diferentes, uso alternativo de los objetos, etc.

- Independencia: grado en que el niño es capaz de realizar cosas en solitario, no pedir ayuda, hacer su tarea concentrado sin reclamar la atención de un adulto, etc.

- Hostilidad: si se enfada rápidamente, no intenta resolver conflictos, se burla de los demás.
- Inteligencia: interés, curiosidad, preguntas adecuadas, amplio vocabulario...

- Orientación a la tarea: concentración en su tarea sin pedir ayuda, disfruta con la tarea, se toma en serio el resultado, intenta hacerla lo mejor que puede...

- Consideración social: se preocupa por los demás, no ofende, espera su turno...

- Dependencia: busca ayuda y la pide incluso para hacer cosas muy simples.

El profesorado nos entregó los cuestionarios de sólo seis menores del asentamiento, y otros nueve de menores que también van al mismo centro escolar, viven en una barriada humilde pero no de pobreza extrema. Los datos de ambos colectivos han sido comparados, para tener unos niveles de referencia que nos ayude a su interpretación.

En el cuadro siguiente (ver Cuadro 5) se señala que existen diferencias estadísticamente significativas en los niveles de extraversión, en la creatividad, y en la inteligencia (Barriada mayor que Asentamiento). Por el contrario, no se observan diferencias significativas en la independencia, dependencia, la consideración social, la orienta- 
ción a la tarea o la hostilidad.

\begin{tabular}{|c|c|c|c|c|c|c|c|}
\hline & & $\mathbf{N}$ & Media & Desviación típica & Mínimo & Máximo & Significatividad \\
\hline \multirow[t]{3}{*}{ *extraversión } & Barriada & 9 & 3,48 & 843 & 1,80 & 4,60 & 019 \\
\hline & Asentamiento & 5 & 2,44 & , 167 & 2,20 & 2,60 & \\
\hline & Total & 14 & 3,11 & ,847 & 1,80 & 4,60 & \\
\hline \multirow[t]{3}{*}{${ }^{* \star}$ creatividad } & Barriada & 10 & 2,96 & ,847 & 1,60 & 3,80 & ,010 \\
\hline & Asentamiento & 6 & 1,86 & ,350 & 1,20 & 2,20 & \\
\hline & Total & 16 & 2,55 & ,877 & 1,20 & 3,80 & \\
\hline \multirow[t]{3}{*}{ Independencia } & Barriada & 10 & 2,80 & ,832 & 1,80 & 4,20 & ,611 \\
\hline & Asentamiento & 6 & 2,60 & ,551 & 1,80 & 3,40 & \\
\hline & Total & 16 & 2,72 & ,726 & 1,80 & 4,20 & \\
\hline \multirow[t]{3}{*}{ Hostilidad } & Barriada & 11 & 2,51 & ,655 & 1,67 & 3,33 & ,066 \\
\hline & Asentamiento & 6 & 1,94 & ,327 & 1,33 & 2,33 & \\
\hline & Total & 17 & 2,31 & ,617 & 1,33 & 3,33 & \\
\hline \multirow[t]{3}{*}{ *inteligencia } & Barriada & 10 & 2,66 & ,748 & 1,60 & 4,00 & 015 \\
\hline & Asentamiento & 6 & 1,73 & ,393 & 1,20 & 2,20 & \\
\hline & Total & 16 & 2,31 & ,776 & 1,20 & 4,00 & \\
\hline \multirow[t]{3}{*}{$\begin{array}{l}\text { Orientación a la } \\
\text { tarea }\end{array}$} & Barriada & 11 & 2,76 & 1,238 & 1,20 & 5,00 & ,522 \\
\hline & Asentamiento & 6 & 3,16 & 1,155 & 2,00 & 5,00 & \\
\hline & Total & 17 & 2,90 & 1,189 & 1,20 & 5,00 & \\
\hline \multirow[t]{3}{*}{ Consideración } & Barriada & 10 & 3,20 & ,941 & 2,00 & 5,00 & ,336 \\
\hline & Asentamiento & 6 & 3,70 & 1,065 & 2,25 & 5,00 & \\
\hline & Total & 16 & 3,39 & ,987 & 2,00 & 5,00 & \\
\hline \multirow[t]{3}{*}{ Dependencia } & Barriada & 11 & 1,75 & ,597 & 1,00 & 2,67 & ,481 \\
\hline & Asentamiento & 6 & 1,94 & , 250 & 1,67 & 2,33 & \\
\hline & Total & 17 & 1,82 &, 501 & 1,00 & 2,67 & \\
\hline
\end{tabular}

Cuadro 5. Desarrollo social en el asentamiento de La Verea. Fuente: Elaboración propia.

Estos resultados pueden interpretarse como que tienen unas actitudes muy adecuadas para facilitar su éxito escolar y compensar las deficiencias previamente observadas, pues muestran el mismo interés que el otro colectivo (orientados a hacer sus tareas), a hacerlo de manera independiente (lo intentan solos), son considerados socialmente con los demás (esperar el turno, no decir algo ofensivo, no herir) y no son dependientes (no piden ayuda cuando no la necesitan). Sin embargo, vuelve a salir la inteligencia y factor verbal, la extraversión y su creatividad (sentido del humor, esperanza, felicidad) como puntuaciones inferiores en los niños y niñas de la Verea -y con diferencias estadísticamente significativas-, observándose cómo estos entornos tan empobre- cidos sí tienen un impacto importante en los menores, y justamente en las dimensiones que más se relacionan con la resiliencia -capacidad de recuperarse ante situaciones traumáticas-.

Parece, pues, que se vuelve a confirmar que los niños y niñas en entornos más empobrecidos no sólo sufren más por su propio entorno, sino que además los aspectos personales, que pueden ser de ayuda para salir de esta situación, también están afectados negativamente. El impacto de la pobreza en el desarrollo infantil se ve demostrado, y especialmente el impacto en las variables relacionadas con la promoción de la resiliencia, y por lo tanto en la posibilidad de mejorar en un futuro. 


\section{Cómo viven: condiciones de supervivencia, problemas y soluciones}

Para explorar sus formas de vida, problemas cotidianos y manera de abordarlos se realizaron entrevistas a las seis familias del asentamiento en marzo de 2011.
Los datos han sido analizados en función de los problemas más frecuentemente presentados, y las soluciones que aplican a los mismos (Ver Cuadro 6). El rango 3 es cuando todas las familias los mencionan, el rango 2 cuando son 4 o 5 familias, y el rango 1 cuando es mencionado por una o dos familias.

\begin{tabular}{|r|l|l|l|}
\hline Rango & Problemas & \multicolumn{2}{|c|}{ Soluciones } \\
\hline 3 & Luz (electricidad) & hogueras y velas & \\
\hline 3 & Despertarse & el gallo & no duerme, mirando el reloj \\
\hline 3 & Frío & bidón con candela & candela y mantas de los reyes \\
\hline 2 & Gomida & pedir & nos tapamos la cabeza con una manta \\
\hline 2 & Goteras, llueve & cambio de cartones & Ilaman a JA, pero no cogen el teléfono \\
\hline 2 & Salud, niños enfermos & pedir para los medicamentos & en un barreño con agua caliente \\
\hline 2 & Aseo & calienta agua y lo hace como puede & \\
\hline 2 & Ropa limpia & lavar a mano & \\
\hline 1 & Agua & los barriles & \\
\hline 1 & Dormir & dos camas y suelo & \\
\hline 1 & Saber & no sabe leer & \\
\hline 1 & Miedo de noche & nos acostamos todos juntos & \\
\hline
\end{tabular}

Cuadro 6. Problemas y soluciones en el asentamiento de La Verea. Fuente: Elaboración propia.

En este Cuadro 6 aparece que los principales problemas que todos abordan y les afectan negativamente a su vida son: la falta de electricidad (luz), que compensan con hogueras y velas; el frío, que igualmente lo combaten con las hogueras y mantas cuando tienen; y se añade el problema de despertarse, dado que todas las familias menos una tienen menores de edad escolar, $y$ tienen que levantarse, preparar el desayuno y llevarlos hasta el autobús; el problema que todas presentan es que no se pueden quedar dormidas pues entonces sus hijos e hijas no pueden ir al centro educativo. Las soluciones que tienen son rudimentarias como escuchar al gallo, o simplemente no dormir, esperando que amanezca. Hay que añadir a la falta de energía y de relojes, la falta de competencias mínimas para saber la hora que es (leer el reloj).

En el segundo grupo aparecen problemas de aseo, ropa limpia, comida, salud de los niños y las goteras cuando llueve. El problema de la comida lo resuelven en el pueblo mendigando, el aseo y la ropa limpia, lavando a mano y calentando agua para asearse mínimamente, en cuanto a la salud de los niños tienen que pedir dinero para adquirir medicamentos, y cuando no pueden llevarlos al hospital o al centro de salud llaman a la ONG que interviene en la zona (responsable del plan integral), pero al parecer nunca cogen el teléfono. El problema de las goteras cuando llueve lo resuelven renovando los cartones que cubren el techo o tapándose con una manta para no mojarse mucho mientras duermen.

En el tercer rango aparecen otros problemas no menos significativos, e igualmente sin soluciones; muy interesante es el problema de no saber, lo cual no lo pueden compensar, pues no saben leer ni nadie les está habilitando programas de alfabetización, a pesar de su interés; el problema de dormir, pues la mayoría lo hace en el suelo, y el 
problema de los pequeños que tienen miedo por la noche (viven entre ratas), lo cual solucionan durmiendo todos juntos (hasta 5 y 6 en una cama, o sobre una manta).

El problema del agua se ha solucionado parcialmente, y la empresa municipal rellena unos depósitos dos veces a la semana.

Como vemos, los problemas que enfrentan en el asentamiento están totalmente condicionados por sus formas de vida, sin unas condiciones básicas que permitan una vida normalizada. Es por ello que cuando hemos preguntado por sus deseos, todas las familias repiten que una casa donde vivir, con luz, y agua, que les permita una vida normal como cualquier ciudadano; también añaden: un trabajo, pues necesitan ocuparse y ser remunerados y gratificados por el trabajo que desempeñan, algo que por ahora tampoco se consigue.

\section{Conclusiones}

El nivel de pobreza y la perpetuidad de la misma deberían ser consideradas por los agentes sociales y educativos como criterio de prioridad para intervenir. El colectivo aquí presentado sufre por vivir en un hábitat de pobreza extrema, tomada tanto por las medidas absolutas como por las relativas, y además crónica, pues no lo son solamente por estos momentos, sino que no recuerdan situaciones mejores en ninguna de sus generaciones pasadas. Son gitanos, colectivo que especialmente en esta zona ha sido duramente castigado, marginado y discriminado durante siglos (Pabanó, 1915).

La calidad de las infraviviendas del asentamiento es simplemente infrahumana. Estas condiciones, unidas a la falta de ingresos, familias numerosas, escasez de espacio y la falta de condiciones mínimas para el aseo o la comida, llevan a ir incrementándose las diferencias en un entorno de pobreza, marginación, exclusión, infraestimulación, malnutrición (Lera et al., 2005). Estos resultados pueden interpretarse como el efecto acumulativo de las microvariables: no sólo es tener un pésimo nivel socioeconómico, sino que además sus hogares son de calidad pésima, lo que tiene un impacto directo en la estimulación y el desarrollo infantil (Lera, 2009).

Los datos señalan que los niños y niñas de pobreza extrema y crónica tienen un desarrollo verbal significativamente menor. Estos datos se confirman en numerosas investigaciones (McLoyd, 1998; National Institute of Child Health and Human Development Early Child Care Research Network, 2005; Werner, 1992). Otras variables consideradas como factores de protección del propio individuo, como puede ser la extroversión, expresividad y creatividad (Rutter, 1987), también están especialmente afectadas en el caso de los niños de pobreza crónica. Sin embargo, su nivel de hostilidad, orientación a la tarea o sociabilidad son iguales que otros colectivos, por lo que tampoco se cumplen los estereotipos extendidos y compartidos por la sociedad en general, que tiende a ver en ellos aspectos negativos que justifican su excepcional situación de pobreza (no quieren trabajar, no son sociables, son agresivos, etc.). Los datos aquí recogidos sirven para confirmar la teoría de que a la pobreza le sigue la pobreza, a menos que se haga algo para evitarla (Garmezy, Masten, \& Tellegen, 1984; Yaqub, 2002). Una situación de pobreza crónica crea un entorno de circunstancias negativas que llevan al menor y a su familia a continuar en un círculo de infortunios, como son enfermedades, malnutrición, analfabetismo, inseguridad, depresión y marginación (Linver, Brooks-Gunn, \& Kohen, 2002).

La falta de estimulación en su propio entorno familiar, unida a la falta de apoyo social, los lleva a un contexto donde todas las microvariables convergen negativamente. Estas circunstancias influyen negativa y directamente en las capacidades 
personales que deberían reforzar para poder superar parte de los obstáculos que la vida les ofrece: la inteligencia, el factor verbal, la extroversión, y la creatividad.

Disponer de unas condiciones mínimas para la vida, unos ingresos y una red de apoyo social son la base para que las variables personales tengan una base real donde sustentarse y promover las variables personales más relacionadas con la autoestima, como son la creatividad, el sentido del humor, la esperanza, la autoestima, la expresividad, el desarrollo lingüístico y el tecnológico.

Estos resultados refuerzan la importancia del momento de la intervención. Si las consecuencias en el desarrollo infantil de tener estas experiencias son tan negativas, la demora en la intervención dará lugar al efecto negativo acumulativo; ante problemas básicos para la supervivencia no encuentran soluciones, como es encontrar comida, disponer de electricidad o simplemente poder levantarse a tiempo. Estas condiciones no hacen más que precipitar acontecimientos negativos y trágicos, como son los accidentes con las velas y los menores, la convivencia con las ratas, el hambre, el frío... que son situaciones muy estresantes, ante las cuales se encuentran impotentes y sin solución, lo cual provoca a su vez un aumento de las enfermedades físicas y mentales, contribuyendo a aumentar la vulnerabilidad del colectivo y el impacto en el desarrollo infantil probablemente hasta límites irreversibles (CombsOrme \& Cains, 2006).

Los datos aquí presentados muestran los efectos en el desarrollo infantil de vivir en la pobreza extrema y crónica, así como la importancia de intervenir lo antes posible con quienes más lo necesitan, algo que parece que las autoridades públicas responsables de garantizar unos mínimos a sus ciudadanos no tienen en cuenta cuando se trata de un colectivo de gitanos y extremadamente marginal y afectado. Se ven sin ayudas justamente quienes más lo necesitan.

\section{Referencias}

BRONFRENBRENNER, Urie \& CECCI, Stephen.

Nature-nurture reconceptualised in developmental perspective: a biological model. Psychological Review,1994, vol. 101, no 4, p. 568-586.

COMBS-ORME, Terri \& CAINS, Daphne S. Poverty and the Daily Lives of Infants. Journal of Children and Poverty, 2006, vol.12, no 1, p.1-20.

DUNN, Lloyd M. Test de Vocabulario en Imágenes Peabody. Adaptación Española. Madrid: MEPSA, 1985.

EMERSON, Eric. Poverty and children with intellectual disabilities in the world's richer countries. Journal of Intellectual \& Developmental Disability, 2004, vol. 29, no 4, p. 319-338.

FUENTES, Juan Luis. Cinco deseos por Navidad: Navidades 2006. Video. Universidad de Sevilla, 2007.

<http://www.psicoeducacion.eu/psicoeducacion/ chabolas/Verea2007.wmv>. (Consultado el 6 de octubre de 2009).

GARMEZY, Norman; MASTEN, Ann S. \& TELLEGEN, Auke. The study of stress and competence in children: A building block for developmental psychopathology. Child Development, 1984, ํㅜ 55, p. 97-111.

LERA, María José. Las ideas de los profesores y su práctica educativa, un estudio en preescolar. Sevilla: Universidad de Sevilla, 1994.

LERA, María José. Proyecto de intervención: atención socioeducativa en el CP Rafael Alberti. Sevilla: Universidad de Sevilla. 2005a. <http://www.psicoeducacion.eu/psicoeducacion/ chabolas/INFORME2.pdf>. (Consultado el 24 de octubre de 2009).

LERA, María José. Proyecto San Rafael. Evaluación del contexto familiar y escolar de la zona. Sevilla: Universidad de Sevilla, 2005b. <http://www.psicoeducacion.eu/psicoeducacion/ chabolas/INFORME1.pdf>. (Consultado el 24 de octubre de 2009). 
LERA, María José (). Asentamiento la Verea, Referencia 08/1143 y 05/3989. Sevilla: Departamento de Psicología Evolutiva y de la Educación de la Universidad de Sevilla, 2008. <http://www.psicoeducacion.eu/node/448>. (Consultado el 24 de octubre de 2009).

LERA, María José. Impacto de la pobreza crónica en la resiliencia; claves para entender la perpetuidad de la miseria. Padeia, 2009, no 46, p. 7397.

$<$ http://www.psicoeducacion.eu/exclusion/impact ०\%20de\%20la\%20pobreza\%20cronica\%20en\% 20la\%20resiliencia\%20apa.pdf>. (Consultado el 4 de noviembre de 2009).

LERA, María José. Declaración: El asentamiento de la Verea del Cerero. 17 de Febrero de 2010. Alcalá de Guadaira: Varias Asociaciones, 2010a.

<http://www.psicoeducacion.eu/laverea/declarac ion_asentamiento_la_verea.pdf>. (Consultado el 24 de octubre de 2009).

LERA, María José. Resumen de lo acontecido el día 19 de Febrero de 2010, a la entrega de la Declaración del Asentamiento de la Verea, y las firmas de apoyo en el ayuntamiento de Alcalá de Guadaíra. Alcalá de Guadaria: Varias Asociaciones, 2010b.

$<$ http://www.psicoeducacion.eu/laverea/acta_res umen_19_de_Febrero.pdf>. (Consultado el 24 de octubre de 2009).

LERA, María José; ALLEPUZ, Carmen \& MATEO, Carolina. Viviendo en chabolas. IV Jornadas de Desarrollo humano y educación. Educar para el cambio: escenarios en el desarrollo humano. Alcalá de Henares, 2005.

LINVER, Miriam; BROOKS-GUNN, Jeanne \& KOHEN, Dafna. (). Family processes as pathways from income to young children's development. Developmental Psychology, 2002, oㅡ 38, p. 719-734.

MASTEN, Ann S.; GARMEZY, Norman; TEL-
LEGEN, Auke; PELLEGRINI, David; LARKIN, Kevin \& LARSEN, Andrea. Competence and stress in school children: the moderating effects of individual and family qualities. Journal of Child Psychology and Psychiatry, 1988, vol. 29, ํo 6, p. 779-914.

MCLOYD, Vonnie C. Socioeconomic disadvantage and child development. American Psychologist, 1998, no 53, p. 185-204.

NATIONAL INSTITUTE OF CHILD HEALTH AND HUMAN DEVELOPMENT EARLY CHILD CARE RESEARCH NETWORK. Duration and developmental timing of poverty and children's cognitive and social development from birth through third grade. Child Development, 2005, vol. 76, no 4, p. 795-810.

PABANÓ, F.M. Historia y costumbres de los gitanos. Barcelona: Montaner y Simón, 1915. (Nueva edición: Sevilla: Extramuros Edición, 2007).

PÉREZ LLORENTE, María Teresa. Acta de la reunión $n^{-} 2$ del ayuntamiento de Alcalá de Guadaíra y agentes educativos implicados en el asentamiento chabolista de la Verea del Cerero. Alcalá de Guadaira: Grupo de Investigación HUM-166, 2006.

<http://www.psicoeducacion.eu/node/2948>. (Consultado el 24 de octubre de 2009).

ROOSA, Mark W; DENG, Shiying; NAIR, Rajni L. \& BURREL, Ginger L. Measuring poverty. Journal of Marriage and Family, 2005, no 67, p. 971988.

RUTTER, Michael. Psychosocial resilience and protective mechanisms. American Journal of Orthopsychiatry, 1987, ํㅡㄴ 57, p. 316-331.

SCHAEFER, Earl S; EDGERTON, Marianna D. \& ARONSON, M. Classroom Behaviour Inventory. Princeton, Educational Testing Service, 1978.

WADSWORTH, Marha E; RAVIV, Talil; REINHARD, Christine; WOLFF, Brian; DE CARLO, Catherine \& EINHORN, Lindsey. An Indirect Effects Model of the Association Between Poverty 
and Child Functioning: The Role of Children's Poverty-Related Stress. Journal of Loss and Trauma, 2008, vol. 13, no 2, p. 156-185.

WERNER, Emily. Overcoming odds: High risk children from birth to adulthood. Ithaca, N.Y: Cornell University Press, 1992.

YAQUB, Shahin. Poor children grow into poor adults: harmful mechanisms or overdeterministic theory? Journal of International Development, 2002, vol. 14, p. 1081-1093.

\section{Cita del artículo}

LERA, M. J. Pobres, gitanos y excluidos: estudio de caso de un asentamiento gitano. Hábitat y Sociedad, 2011, no 3, p. 51-65. <www.habitatysociedad.us.es>.

http://dx.doi.org/10.12795/HabitatySociedad.2011.i3.04 